\title{
Counterfeit Money Detection Algorithm using Non-Local Mean Value and Support Vector Machine Classifier
}

\author{
Sang-Keun $\mathrm{Ji}^{\dagger} \cdot$ Hae-Yeoun Lee ${ }^{+\dagger}$
}

\begin{abstract}
Due to the popularization of digital high-performance capturing equipments and the emergence of powerful image-editing softwares, it is easy for anyone to make a high-quality counterfeit money. However, the probability of detecting a counterfeit money to the general public is extremely low. In this paper, we propose a counterfeit money detection algorithm using a general purpose scanner. This algorithm determines counterfeit money based on the different features in the printing process. After the non-local mean value is used to analyze the noises from each money, we extract statistical features from these noises by calculating a gray level co-occurrence matrix Then, these features are applied to train and test the support vector machine classifier for identifying either original or counterfeit money. In the experiment, we use total 324 images of original money and counterfeit money. Also, we compare with noise features from previous researches using wiener filter and discrete wavelet transform. The accuracy of the algorithm for identifying counterfeit money was over 94\%. Also, the accuracy for identifying the printing source was over 93\%. The presented algorithm performs better than previous researches.
\end{abstract}

\section{Keywords : Counterfeit Money Detection, Non-Local Mean Value, Gray Level Co-occurence Matrix, Support Vector Machine Classifier}

\section{비지역적 특징값과 서포트 벡터 머신 분류기를 이용한 위변조 지폐 판별 알고리즘}

\author{
지 상 근 ${ }^{+} \cdot$ 이 해 연 ${ }^{++}$
}

\section{요 약}

디지털 고성능 영상장비의 대중화와 강력한 이미지 편집 소프트웨어의 출현으로 인해 고품질의 위·변조가 가능하게 되었다. 특히 화폐 위. 변조 범죄가 급격히 증가하고 있지만, 일반인이 위·변조 지폐를 발견하는 비율은 낮은 수준이다. 본 논문에서는 범용 스캐너를 이용하여 위·변 조 지폐를 판별할 수 있는 알고리즘을 제안한다. 본 알고리즘에서는 위·변조 지폐를 출력하는 과정에서 나타나는 인쇄물의 고유한 특징에 기반 하여 위·변조 여부를 판별한다. 비지역적 평균 알고리즘을 이용하여 인쇄 과정에서 나타나는 노이즈 특성을 추출하고, 명암도 동시발생 행렬을 계산하여 지폐의 특징값을 추출하였다. 추출한 지폐의 고유한 특징값을 학습기반 데이터 분류기에 적용하여 위·변조 여부를 판별하였다. 제안한 알고리즘의 성능을 분석하기 위해 총 324 장의 1 만원권 지폐와 8 대 프린터에서 출력한 위조지폐 이미지로 실험하였다. 또한 노이즈 추출에 있어 기존 프린터 판별 기술에서 사용되었던 위너필터와 이산웨이블릿변환 기반 알고리즘과 비교 분석을 수행하였다. 그 결과 제안한 알고리즘이 위·변조 판별에 있어서 $94 \%$ 이상의 정확도를 보였으며, 위·변조 지폐 인쇄기기 식별에 있어서는 $93 \%$ 이상의 정확도를 보여서 기존 프린터 판 별 기술을 이용한 것보다 우수함을 보였다.

키워드 : 위변조 지폐 판별, 비지역적 평균값, 명암도 동시발생 행렬, 학습기반 분류기

\section{1. 서 론}

※ 이 논문은 2012년도 정부(교육과학기술부)의 재원으로 한국연구재단의 지원을 받아 수행된 기초연구사업임(2012-0002862)

† 준 회 원: 국립금오공과대학교 컴퓨터소프트웨어공학과 학사과정

†† 정 회 원 : 국립금오공과대학교 컴퓨터소프트웨어공학과 교수 논문접수 : 2012 년 6 월 1 일

수 정 일 : 1 차 2012년 9월 2일, 2차 2012년 10월 8일

심사완료 : 2012 년 10월 23일

* Corresponding Author:Hae-Yeoun Lee(haeyeoun.lee@kumoh.ac.kr)
컴퓨터와 디지털 기기의 대중화와 고화질의 영상에 대한 관심과 요구로 인해 디지털 기기의 디지털 고성능 영상장비 를 저렴한 가격으로 누구나 쉽게 구매할 수 있다. 또한 고 화질의 영상을 얻을 수 있게 됨에 따라 정밀한 편집 기술에 대한 관심과 강력한 이미지 편집 소프트웨어의 출현으로 인 


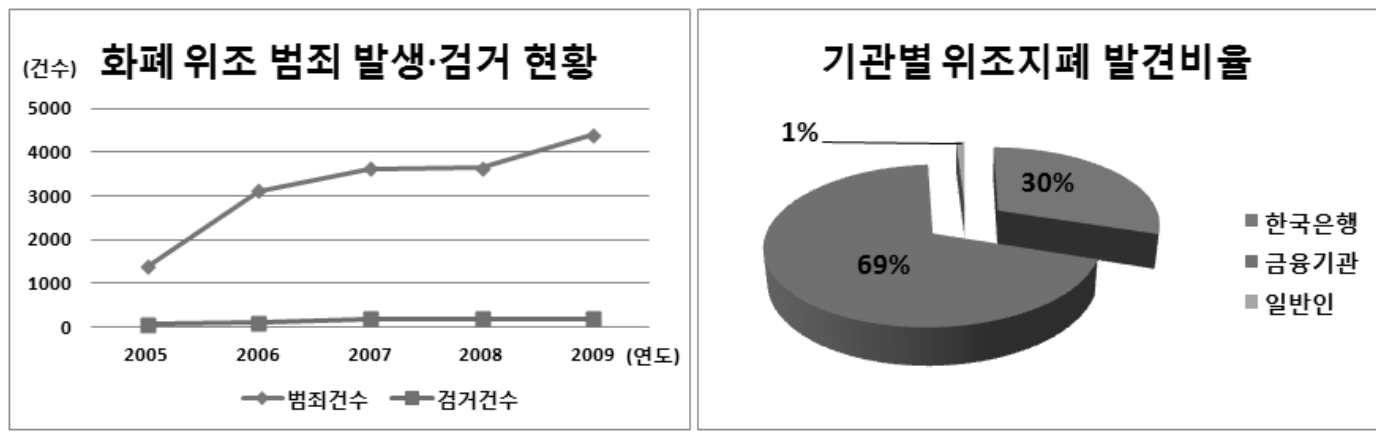

Fig. 1. Counterfeit money crime statistics and detection rate

해 손쉬운 이미지 편집이 가능하게 되었다. 이로 인해 일반 인들도 손쉽게 위·변조를 할 수 있게 되면서, 사회적인 위· 변조 범죄가 증가하고 있다.

특히 각종 인쇄물의 위·변조 범죄 중에서 화폐 위조범죄 가 급격히 증가하고 있다. Fig. 1과 같이 화폐 위조 범죄의 발생은 해가 거듭될수록 급격히 증가하는데 비해 검거 건수 는 극히 미미하다. 또한, 일반인이 위조지폐를 발견하는 비 율은 채 $1 \%$ 밖에 되지 않는다. 기존의 위·변조 지폐 판별 장 치을 위한 기술의 경우에는 지폐의 마그네틱과 자외선, 적 외선 같은 물리적이거나 광학적인 특성을 이용하고 있으며, 고가의 장비에 해당한다. 또한, 적용되는 보안 기술들이 다 양하기 때문에 범용적인 지폐 위변조의 판별이 어렵고, 지 폐의 종류마다 판별 장치를 구입하는데 높은 비용이 필요하 므로 일반인에게 보급이 어렵다.

본 논문에서는 손쉽게 다양한 위·변조 지폐의 판별이 가 능하며, 저렴한 비용으로 구축 가능한 범용 스캐너를 이용 하며, 지폐의 인쇄과정에 나타나는 특성을 이용하여 위·변조 지폐 판별 알고리즘을 제안한다. 비지역적 평균 알고리즘을 이용하여 위·변조 지폐를 출력하는 과정에서 나타나는 인쇄 물에 숨겨져 있는 고유한 특징인 노이즈 특성을 추출한다. 이에 대해 명암도 동시발생 행렬을 생성한 후에 통계적인 특징값인 유사성, 대조, 합계, 상관관계, 공분산을 계산한다. 계산한 특징값을 학습기반 데이터 분류기에 적용하여 위·변 조 여부를 판별한다.

본 논문의 구성은 다음과 같다. 2절에서는 인쇄물에 대한 기존의 특징 추출 방법에 대해 소개하고, 3절에서는 제안하 는 위·변조 지폐 판별 알고리즘을 설명한다. 4절에서는 실험 결과를 제시하고 5절에서는 결론을 짓도록 하겠다.

\section{2. 관련 연구}

위·변조 지폐 판별 알고리즘의 성능은 인쇄된 지폐에 존 재하는 고유한 특징의 정확한 추출에 의해 좌우된다. 그러 나 범용적인 장비를 사용하여 위변조 지폐를 판별하는 기존 연구들은 부재한다. 기존에 인쇄물의 특징을 활용하여 인쇄 에 사용된 프린터를 판정하는 연구들이 진행되었고 본 절에 서 이를 위한 특징들에 대해서 간략히 설명한다[1-3].

\section{1 위너필터를 이용한 노이즈 특성 추출}

위너필터란 비정상성 잡음을 제거하는 데 유용한 필터로 최소자승 필터라고 한다. 이를 이용하여 입력 영상에서 의 도하지 않게 들어가 튀는 값들을 제거하여, 잡음을 제거한 이미지를 얻을 수 있다.

위너필터를 이용한 노이즈 특성 추출은 Fig. 2 와 같이 원 본 이미지에서 위너필터를 이용하여 잡음이 제거된 이미지 의 차이를 계산함으로써 노이즈 특성을 추출하는 방법으로 Lee et al.에서 인쇄물의 특징을 추출하는데 사용되었다[1].
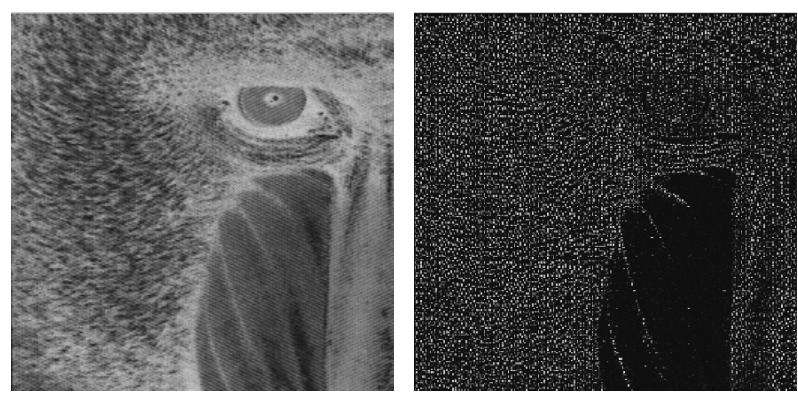

Fig. 2. Noise extraction using Wiener filter

디지털 이미지의 인쇄 과정에서 프린터가 문서를 출력할 때는 $\mathrm{RGB}$ 영역을 $\mathrm{CMY}$ 영역으로 변환하여 출력한다. 그렇 기 때문에 스캔한 이미지를 $\mathrm{RGB}$ 영역에서 $\mathrm{CMY}$ 영역으로 변환하여 각 영역에 대해 위너필터를 적용시킨다. 위너필터 를 적용하여 노이즈를 제거한 이미지를 원본 이미지와의 차 이 연산을 통해 인쇄 과정에서 나타나는 고유한 특징인 노 이즈 특성을 추출한다. Fig. 3에 지폐 이미지에 위너필터를 적용하여 노이즈 특성을 추출한 결과를 도시하였다.

\section{2 이산웨이블릿변환를 이용한 노이즈 특성 추출}

이산 웨이블릿 변환(Discrete Wavelet Transform: DWT) 을 이용하여 노이즈 특성을 추출하는 방법은 출력과정에서 색을 재구성하는 방법이 인쇄 장치마다 다르다는 점에 착안 한 방법으로 Choi가 제안하였다[2]. Choi는 이산 웨이블릿 변 환을 이용하여 만들어진 고주파 $(\mathrm{HH})$ 영역이 노이즈에 대한 정보를 담고 있으며, 이 정보가 인쇄 장치마다 많이 다르다 는 것을 활용하여 노이즈 특성 추출 방법을 연구하였다. 
이와 같이 이산 웨이블릿 변환의 고주파 성분을 노이즈 특성으로 사용하는 방법은 Choi et al. [2]와 Baek et al. [3] 에서 사용되었다. 이산 웨이블릿 변환의 기본적인 동작은 $\mathrm{n}$ 개의 샘플을 갖는 이산 신호에 적용된다. 신호에 대해 한 쌍의 필터를 적용시켜 고주파 대역과 저주파 대역으로 분리 한다. 각 대역은 2 라는 요소로 서브 샘플링이 되었으므로 $\mathrm{n} / 2$ 개의 샘플을 포함한다. 2 차원 이미지의 각 행에 대해 저 역 통과 필터와 고역 통과 필터를 적용시키고 2 로 다운 샘 플링을 수행하여 4 개의 서브 이미지인 $\mathrm{LL}, \mathrm{LH}, \mathrm{HL}, \mathrm{HH}$ 가 얻어진다. LL은 원본 이미지에 수평과 수직방향으로 저역 통과 필터를 적용하여 2 로 서브 샘플링 된 것이며, $\mathrm{LH}$ 는 수 평 방향으로 고역 통과 필터를 적용한 것으로 수평 방향 주 파수의 오차 성분을 포함한다. $\mathrm{HL}$ 은 수직방향으로 고역 통 과 필터를 적용하여 수직 방향의 주파수의 오차 성분을 포 함하고, $\mathrm{HH}$ 는 수평과 수직 방향에 고역 통과 필터를 적용 한 것이다.

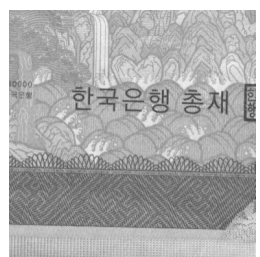

(a) Money image

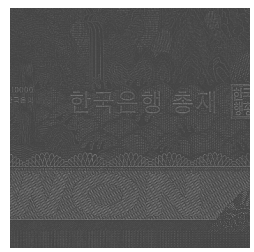

(d) C channel noise image

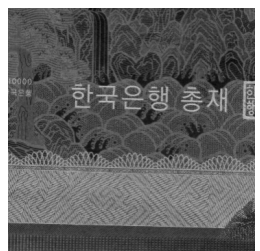

(b) CMY domain image

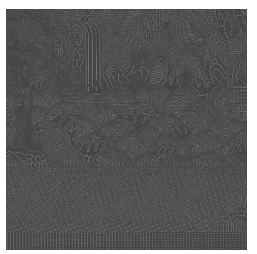

(e) M channel noise image

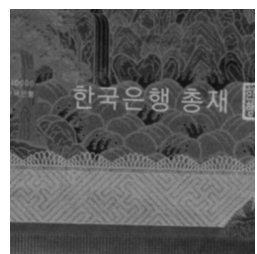

(c) Image after wiener filter

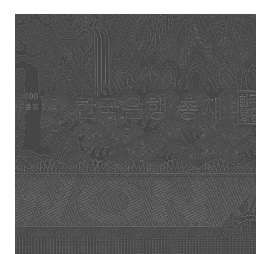

(f) Y channel noise image
Fig. 3. Noise example of money using wiener filter
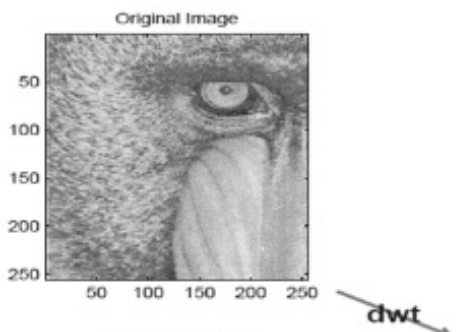

Diagonal detall coet at level 1

synthesized image
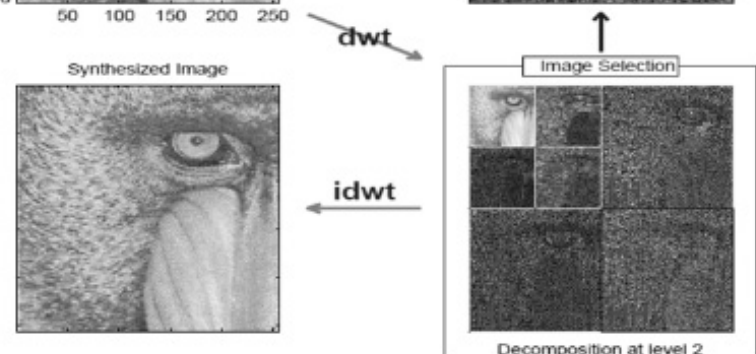

Fig. 4. Noise extraction using discrete wavelet transform
Fig. 4와 같이 영상에 대해 이산 웨이블릿 변환을 통해 저역 필터와 고역 필터를 두 번 거친 4 개의 주파수 성분 $(\mathrm{LL}, \mathrm{LH}, \mathrm{HL}, \mathrm{HH})$ 으로 분할하고, 그 결과 고주파 성분인 $\mathrm{HH}$ (High-High)영역을 추출하여 노이즈 특성으로 이용한다.

Fig. 5에는 지폐 영상에 대하여 인쇄물의 노이즈 특성 정 보를 활용하기 위해, 이미지를 RGB 영역에서 $\mathrm{HSV}$ 영역으 로 변환한 후에, 각 $\mathrm{HSV}$ 영역에 대해 이산 웨이블릿 변환 을 수행하여 노이즈 특성을 추정한 $\mathrm{HH}$ 영역에 대한 결과를 도시하였다.

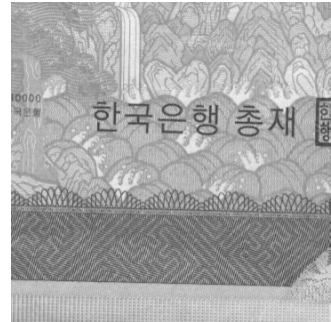

(a) Money image

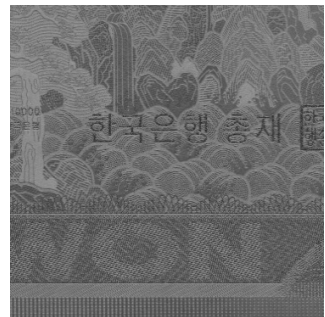

(b) HSV domain image
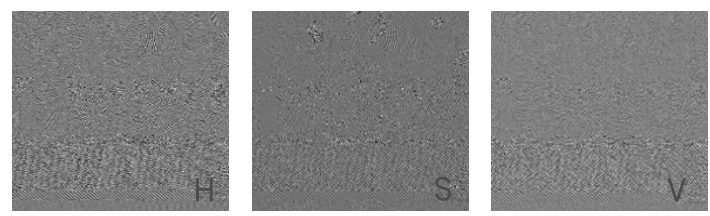

(c) High frequency $(\mathrm{HH})$ image in HSV domain

Fig. 5. Noise example of money using discrete wavelet transform

\section{3 허프 변환를 이용한 이미지 특징 추출}

컬러 레이저프린터는 CMYK(Cyan, Magenta, Yellow, Black)의 4가지 색상을 조합하여 색을 표현한다. 지폐 이미 지를 조합된 4가지 색상으로 분리하여 확대해 보면 색상마 다 일정한 패턴을 확인할 수 있다.

Fig. 6은 프린터마다 가지는 고유한 패턴인 주기적인 무 늬를 나타낸다. Ryu et al.은 이와 같은 특성을 활용하여 패

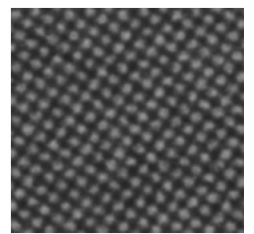

(a) Canon iR C2620

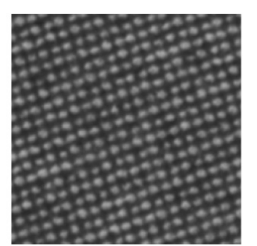

(c) Konica Minolta Bizhub C250

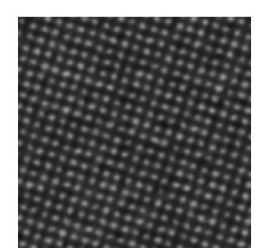

(b) $\mathrm{HP} 4650$

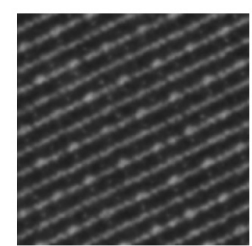

(d) Xerox DCC450
Fig. 6. Frequent texture of cyan channel for each printer 

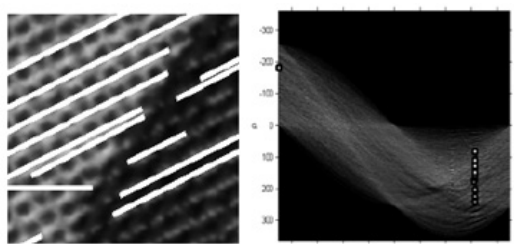

(a) Xerox DCC450
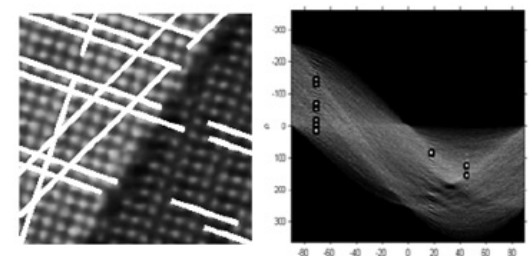

(b) HP 4650 (Edge Area)
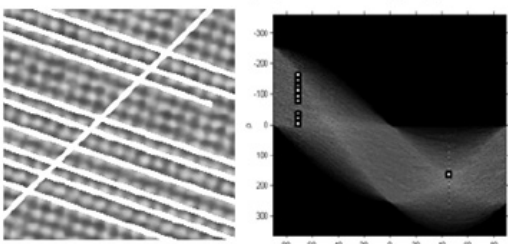

(c) HP 4650 (Smooth Area)
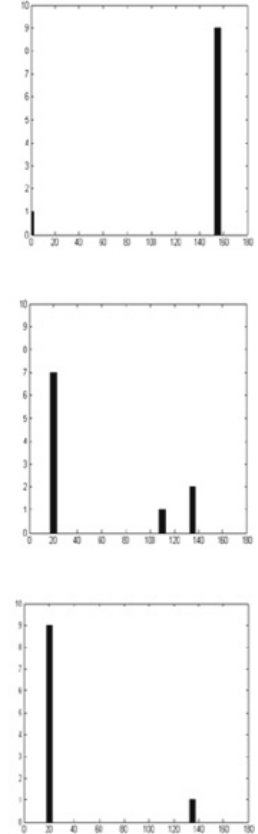

ar histogram feature values after hough transform of cyan channel

턴에 존재하는 선형 특성의 방향성 정보를 허프 변환 (Hough Transform)을 이용하여 추출하여 컬러 레이저프린 터를 판별하는 기술을 연구하였다[4].

입력된 영상에서 에지 정보를 추출하여, 허프 변환을 통 해 라인 정보를 추출한다. 추출한 라인의 각도에 따른 히스 토그램을 계산하여 프린터 판별을 위한 특징값으로 사용한 다. Fig. 7은 이미지의 허프 변환 후에 라인의 각도에 대한 히스토그램을 나타낸다. 그림과 같이 다른 프린터와는 각도 히스토그램의 차이가 있음을 확인할 수 있다. 위의 과정을 통해 지폐의 인쇄과정에 존재하는 특징값을 이용하여 지폐 의 위변조 여부를 판별할 수 있다. 하지만 허프 변형을 이 용한 방법은 출력된 이미지가 가지는 패턴을 확인할 수 있 는 고해상도 이미지가 필요하므로 저해상도 이미지에는 적 용하기 힘든 단점이 있다.

\section{3. 제안하는 위·변조 지폐 판별 알고리즘}

본 논문에서 제안하는 위·변조 지폐 판별 알고리즘은 훈 련 및 판별의 2 단계로 구성되어진다. 제안하는 알고리즘의 대략적인 수행 과정은 Fig. 8에 도시되어 있다.

훈련 과정에서는 원본 지폐와 위·변조 지폐를 스캔한 이 미지를 사용하여 특징점 추출기를 통해 각 지폐의 고유한 특징을 추출하고, 학습기반 데이터 분류기의 파라미터로 입 력하여 훈련을 수행한다.

판별 과정에서는 임의의 지폐가 데이터가 들어왔을 때, 특징점 추출기를 통해 특징을 추출하고, 훈련된 학습기반 데이터 분류기에 입력하여, 입력된 지폐가 원본인지 위·변조
본인지 판별을 수행한다. 또한 위·변조 지폐인 경우 어떤 인 쇄 기기로 출력이 된것인지 식별한다.

본 논문에서 제안하는 비지역적 평균값을 이용한 노이즈 특성 추출에 대해 3.1.1절에서 설명하고, 3.1.2절에서는 명암 도 동시발생 행렬을 통한 특징값 계산, 3.2절에서는 학습기 반 데이터 분류기에 대해서 설명한다.

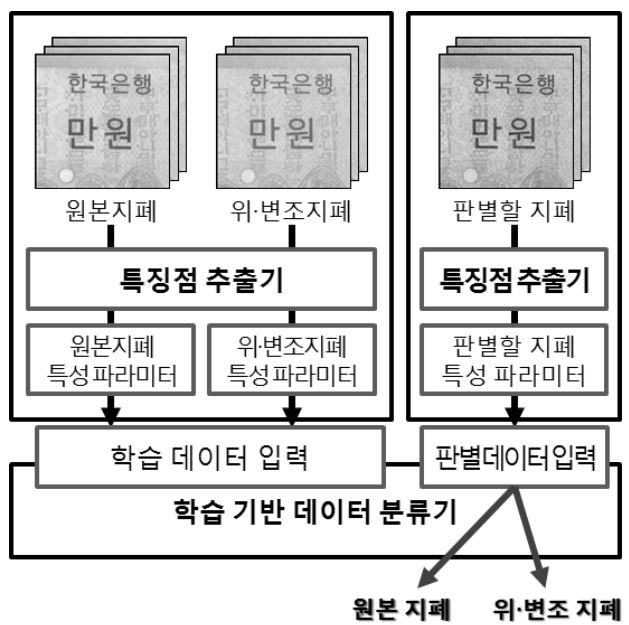

Fig. 8. Counterfeit money detection algorithm

\section{1 특징 추출}

제안하는 판별 기술의 성능은 고유한 특징에 대한 정확한 추출과, 추출된 특징의 학습 분류기를 통한 올바른 분류 기 능에 의하여 좌우된다. 본 연구에서는 지폐 이미지에 존재 하는 고유한 특징을 추출하기 위하여 다양한 특징점에 대한 연구를 수행하였다.

그리고, Fig. 9에 나타난 것과 같이 가장 최적의 결과를 나타내는 비지역적 평균값을 이용하여 노이즈 특성을 추출 하고, 이에 대해 명암도 동시발생 행렬을 생성하고 통계적 인 특징을 추출하는 방법을 설계하였다.

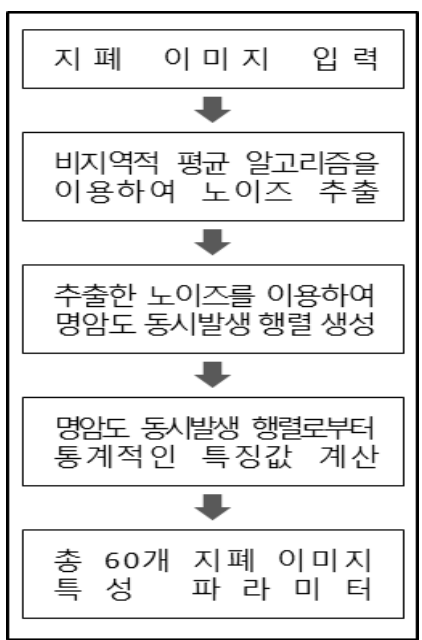

Fig. 9. Feature extraction steps 
1) 비지역적 평균 알고리즘을 이용한 노이즈 특성 추출

비지역적 평균(non-linear local means) 알고리즘은 영상 노이즈 제거 알고리즘 중에 하나로서 노이즈 제거에 우수한 성능을 보인다. 이는 노이즈를 제거하고자 하는 화소의 주 변 집합에서 주변 집단 영역과의 유사성을 비교하고 유사한 정도에 따라 가중치를 주어서 이를 기반으로 평균을 구하는 노이즈 제거 알고리즘이다 [5]. 그러나 주변 화소들의 집합 크기를 일정 크기로 한정짓지 않고 이미지 전체로 확장하여 적용하므로, 다른 노이즈 제거 알고리즘보다 성능이 뛰어나 지만 연산 속도가 느린 단점이 있다.

비지역적 알고리즘의 다른 노이즈 제거 알고리즘과의 주요 한 차이점은 이미지가 존재하는 모든 픽셀 정보를 조직적으로 이용하여 자기 예측을 최대한으로 가능하게 한다는 것이다.

주어진 노이즈 이미지 $v=v(i) \mid i \in I$ 에 대해 픽셀 $i$ 에 대한 예측값인 $N L[v](i)$ 는 이미지에서 모든 픽셀의 가중 평균으로 계산되어 다음과 같이 표현할 수 있다.

$$
N L[v](i)=\sum_{\mathrm{j} \in I} w(i, j) v(j)
$$

여기서 $w(i, j)$ 는 픽셀 $i$ 와 $j$ 에 대한 가중치로 두 픽셀 간의 유사성에 의존적이며 다음의 상태를 만족한다.

$$
0 \leq w(i, j) \leq 1 \text { and } \sum_{j} w(i, j)=1
$$

또한, 위의 두 픽셀간의 유사성을 나타내는 가중치는 gray level 벡터인 $v\left(N_{i}\right)$ 와 $v\left(N_{j}\right)$ 의 유사성에 의존한다. 여기서 $N_{k}$ 는 픽셀 $k$ 에 중심이 있는 고정된 크기의 정방 이웃을 나타낸다. 이 유사성은 편중된 유클리디안 거리의 감소함수로 측정되며, 노이즈 이웃들에 대한 유클리디안 거 리의 적용은 다음의 식으로 표현된다.

$$
E\left\|v\left(N_{i}\right)-v\left(N_{j}\right)\right\|_{2, a}^{2}=\left\|v\left(N_{i}\right)-v\left(N_{j}\right)\right\|_{2, a}^{2}+2 \sigma^{2}
$$

상기의 기대값에서 유클리디안 거리는 픽셀들 간의 유사 성에 대한 순서를 보존하기 때문에 알고리즘의 강인함을 보 여준다. Fig. 8과 같이 $v\left(N_{i}\right)$ 에 유사한 gray level 이웃의 픽셀들은 평균적으로 큰 가중치를 가지며 가중치는 다음 식 으로 표현된다.

$$
\begin{gathered}
w(i, j)=\frac{1}{Z(i)} e^{-\frac{\left\|v\left(N_{i}\right)-v\left(N_{j}\right)\right\|_{2, a}^{2}}{h^{2}}} \text { where } \\
Z(i)=\sum_{j} e^{-\frac{\left\|v\left(N_{i}\right)-v\left(N_{j}\right)\right\|_{2, a}^{2}}{h^{2}}}
\end{gathered}
$$

여기서 $Z(i)$ 는 정규화 상수이며, $h$ 는 필터링의 정도를 나타내는 파라미터이다. 상기의 식에서 $h$ 는 지수함수의 감 소를 제어하므로, 결국 유클리디안 거리의 가중치 감소를 제어한다.

또한 비지역적 평균 알고리즘은 단일점에서의 gray level 을 비교할 뿐만 아니라, 전체적인 이미지의 이웃에 대한 기 하학적인 형태를 비교하므로 다른 neighborhood filters보다 강인한 비교를 할 수 있다. Fig. 10과 같이 픽셀 $\mathrm{q} 3$ 는 $\mathrm{p}$ 와 같은 gray level의 값을 가지지만, 이웃의 값이 다르므로 $w(p, q 3)$ 의 가중치는 거의 0 에 가깝다.

비지역적 평균 알고리즘의 계산량 제한을 위하여, 유사한 이웃을 나타내는 탐색 윈도우의 범위를 $\mathrm{SxS}$ 크기로 제한해 야 한다. 검색 윈도우의 크기가 크면 클수록 노이즈를 제거 하는데 유사한 픽셀을 찾을 수 있으므로 우수한 성능을 보 인다. 하지만, 그에 따른 계산량이 급격히 증가하므로 노이 즈 제거 속도가 느려지게 된다.

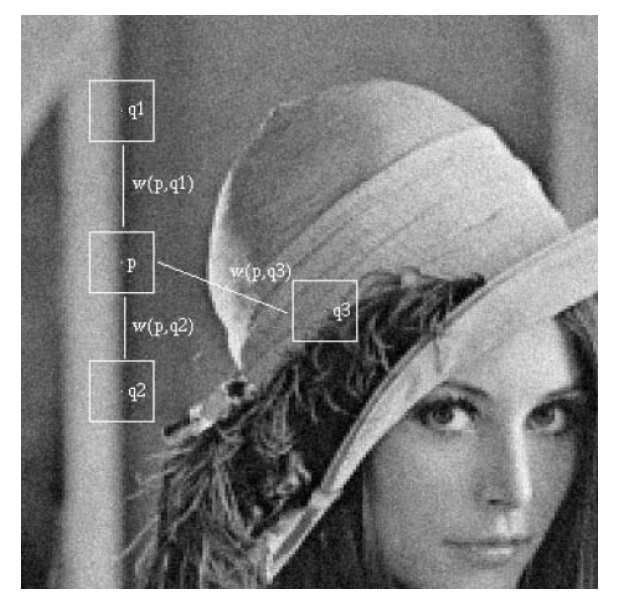

Fig. 10. Example of non-local mean algorithm

앞서 본 가중치는 유클리디안 거리의 제곱에 비례하며, 검 색 윈도우 크기를 $(2 \mathrm{f}+1) \mathrm{x}(2 \mathrm{f}+1)$ 로 정의한다면 픽셀 $p, q$ 에 대한 유클리디안 거리의 제곱은 다음의 식으로 표현된다.

$$
\begin{aligned}
& d^{2}(B(p, f), B(q, f)) \\
& =\frac{1}{3(2 f+1)^{2}} \sum_{i=1}^{3} \sum_{j \in B(0, f)}\left(u_{i}(p+j)-u_{i}(q+j)\right)^{2}
\end{aligned}
$$

여기서 $B(p, r)$ 은 픽셀 $\mathrm{p}$ 에 중심이 위치한 $(2 \mathrm{r}+1) \mathrm{x}(2 \mathrm{r}+1)$ 크기의 이웃을 의미한다. 이에 따른 가중치는 다음의 식으 로 표현할 수 있다.

$$
w(p, q)=e^{-\frac{\max \left(d^{2}-2 \sigma^{2}, 0.0\right)}{h^{2}}}
$$

$\sigma$ 는 노이즈의 표준편차를 나타내며, $\mathrm{h}$ 는 $\sigma$ 에 의존적인 필터링 파라미터로 $h=10^{*} \sigma$ 로 고정된다. $\sigma$ 가 증가하면 
강인한 패치 비교를 하기 위해 패치의 크기를 크게 증가시 켜야 하며, 동시에 더 유사한 픽셀들을 찾음으로써 알고리 즘의 노이즈 제거 성능 향상을 하기 위해 검색 윈도우 크기 도 증가시켜야 한다.

본 연구에서는 실험적으로 노이즈 제거 성능과 그에 따른 시간에 대해 최상의 결과를 나타내는 $\sigma$ 의 값을 7 로 얻어냈 으며 그에 따라 검색 윈도우의 크기를 $3 \times 3$, 블록 크기를 10 으로 설정하였다. 입력받은 지폐 이미지를 RGB 영역으로 분할하여 각 $\mathrm{RGB}$ 영역별로 비지역적 평균 알고리즘을 이용 하여 노이즈 제거 이미지를 얻었다. 이를 원본 이미지와의 차이 연산을 통해 Fig. 11와 같이 노이즈 특성 이미지를 추 출할 수 있다.

\section{2) 명암도 동시발생 행렬을 이용한 특징점 추출}

명암도 동시발생 행렬(Gray Level $\mathrm{Co}^{-}$occurrence Matrix : $\mathrm{GLCM})$ 은 화소 기반의 통계적 질감영상 생성을 위해 Haralick et al.에 의해 제안되었다[6]. 질감영상의 응용 연구 에서는 영상 분류 단계에서 질감영상을 추가적으로 적용하는 경우, 정성적인 분류 결과와 정량적인 분류 정확도의 향상에 질감영상이 유용한 자료임이 여러 사례연구에서 밝혀졌다. 그 러나 질감영상이 유용함에도 불구하고, 질감영상의 선택 기준 에 대한 연구 결과는 실제적으로 제시된 바가 거의 없다.

영상의 질감적인 특성을 잘 드러나게 하기 위해 명암도 동시발생 행렬을 이용한다. 명암도 동시발생 행렬이란 영상 내에서 픽셀간의 밝기 값의 관계를 나타내는 방법으로 이미 지의 인접한 방향의 두 픽셀의 값을 좌표 값으로 이용하여, 좌표 값의 출현빈도를 나타내는 행렬이다. Fig. 12과 같이 좌표 값의 출현빈도는 영상에서 $0^{\circ}, 45^{\circ}, 90^{\circ}, 135^{\circ}$ 의 4 가지 방향에 대해 명암도 동시발생 행렬을 생성하였다.

입력된 영상에 대하여 명암도 동시 발생 행렬로 변형을 수행한 후에 Table 1에 나타난 것과 같이, 유사성, 대조, 합 계, 상관관계, 공분산의 5 가지 통계적인 특성을 사용하여 각 특징점을 추출하였다.
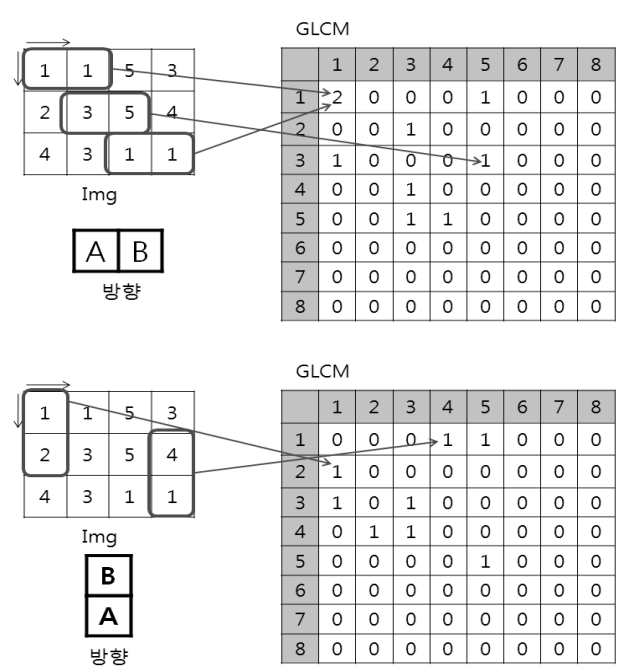

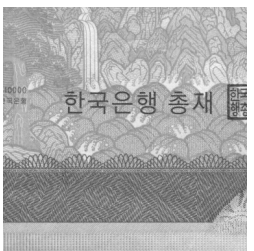

(a) Money image

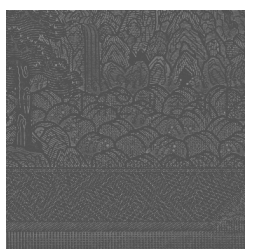

(c) R channel noise image

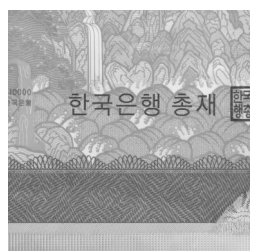

(b) Non-local mean filtered image

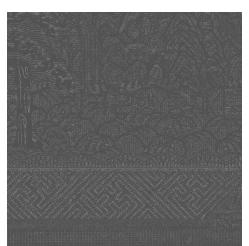

(d) G channel noise image

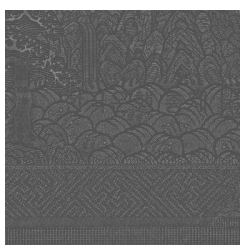

(e) B channel noise image
Fig. 11. Noise images using non-local mean algorithm

본 연구에서는 지폐 이미지의 특징점 추출을 위해 앞서 추출한 노이즈 특성을 $\mathrm{CMY}$ 영역으로 변환하여 각 영역마 다 $0^{\circ}, 45^{\circ}, 90^{\circ}, 135^{\circ}$ 의 4 가지 방향에 대한 명암도 동시발생 행렬을 계산하였다. 계산한 행렬로부터 Table 1 와 같이 통 계적인 특성인 유사성, 대조, 합계, 상관관계를 각 영역별로 추출하고, $\mathrm{C}$ 와 $\mathrm{M}, \mathrm{M}$ 과 $\mathrm{Y}, \mathrm{Y}$ 와 $\mathrm{C}$ 영역간의 공분산을 계산 하여 총 60 개의 지폐 이미지 특징점을 추출하였다. 이 특징 점들은 학습기반 데이터 분류기에서 위·변조 여부를 판별하 는데 훈련 및 판별 데이터로 이용된다.

\section{2 학습기반 데이터 분류기}

학습기반 데이터 분류기로서 Support Vector Machine (SVM) 분류기는 분류와 회귀 분야에서 쓰이는 학습 방법들 중 하나로, 1995년 통계학자인 Vladimir Vapnik에 의하여 제안된 Fig 13a와 같이 이진분류를 위한 학습 알고리즘이다 [7]. 이진분류란 수집된 데이터를 이용하여 구조적 위험 최
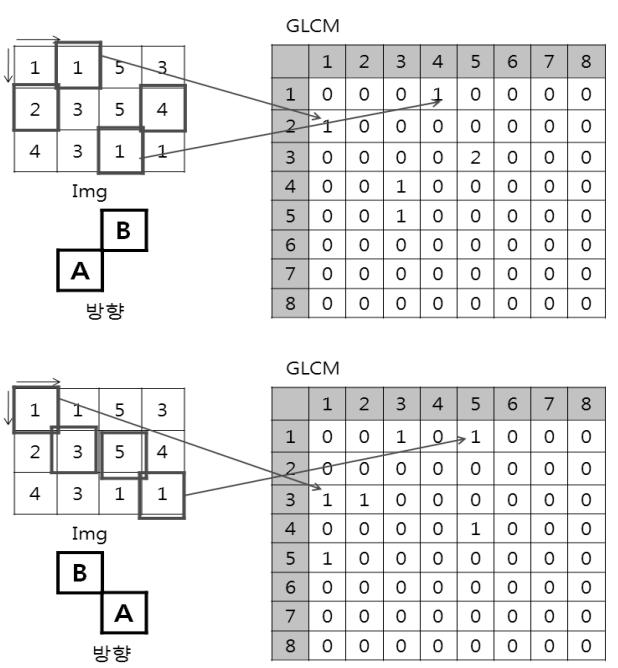

Fig. 12. Calculation of gray-level co-occurrence matrix 
Table 1. Feature values from gray-level co-occurrence matrix

\begin{tabular}{|c|c|c|}
\hline Feature & Equation & Description \\
\hline Homogeneity & homogeneity $=\sum_{i, j} \frac{p(i, j)}{1+|i-j|}$ & It represents the uniformity of pixels \\
\hline Contrast & contrast $=\sum_{i, j}|i-j|^{2} p(i, j)$ & It represents intensity difference between pixels \\
\hline Sum & energy $=\sum_{i, j} p(i, j)^{2}$ & It represents the summation of pixel intensity values \\
\hline Correlation & correlation $=\sum_{i, j} \frac{(i-\mu i)(j-\mu j) \vec{p}(i, j)}{\sigma_{i} \sigma_{j}}$ & It represents the correlation between pixels \\
\hline Covariance & Cov $\left(I_{1}, I_{2}\right)=\frac{1}{N_{x, y}} \sum^{N} I_{1}(x, y) \times I_{2}(x, y)$ & It represents how two pixels are correlated to change \\
& $-\frac{1}{N_{1}} \sum_{x, y=1}^{N}\left((I(x, y)-\overline{I(x, y)})^{3}\right)$ & together \\
\hline
\end{tabular}

소화의 개념에 기반으로 하여 최적의 선형 결정 평면을 구 하는 것이다. 현재 SVM 분류기은 생물정보학, 문자인식, 필 기인식, 얼굴 및 물체 인식 등 다양한 분야에서 성공적으로 적용되고 있다.

SVM 분류기는 Fig. $13 b$ 와 같이 입력된 훈련 데이터를 고차원의 특정 공간에 사상하여, 서로 다른 클래스로 분류 시키는 초평면 중에서 여백을 최대화시키는 특정한 초평면 인 최대 여백 초평면을 찾는 것을 목적으로 한다. 최대 여 백 초평면에 가장 근접한 훈련데이터를 Support Vector라고 부르며, 이를 포함하는 초평면 사이의 여백값이 클수록 분 류 성능이 좋아진다.

SVM 분류기는 분리 경계가 매우 복잡한 문제를 선형 판 별함수의 사용이 가능한 단순한 문제로 변환시키기 때문에 수학적인 분석이 수월하다는 장점이 있다. 또한, 적은 양의 학습 데이터만으로도 분류 성능이 우수하다. SVM 분류기는 학습오류를 최소화하는 경험적 위험 최소화를 기반으로 하 는 기존 원리에 비하여, 전체집단을 하위집단으로 세분화한 뒤 이 집단에 대한 경험적 위험도를 최소화하는 구조적 위 험 최소화 개념에 기초하여 일반화 성능이 우수하며 비선형 분리 문제와 같은 복잡한 분류문제를 해결하기 위해 다양한 커널을 제공한다.

SVM 분류기는 LIBSVM, SVM light, SVM Torch 등 다 양한 소프트웨어들이 공개적으로 사용 가능하며, 다른 기계 학습 방법들보다 상대적으로 사용하기 쉬운 장점이 있다. SVM 분류기를 사용할 때에는 목적에 맞는 커널과 그에 따 른 커널 변수를 선택하면 된다. 또한, 새로운 패턴이 나타난 다면 훈련 과정에서 모델을 동적으로 갱신할 수 있다.

본 논문에서는 위의 SVM 분류기 중에서 다중 클래스 분 류를 지원하는 LIBSVM을 사용하였다 [8, 9]. LIBSVM은 unbalanced 클래스에 대해 페널티 부가 기능을 가지고 있어 서, 다중 클래스를 확실하게 분류하기 위해 사용자가 초평
면을 결정하는데 있어서 분류 오류를 최소화시킬 수 있다.

본 연구에서는 Support Vector Machine 분류기을 이용하 여 앞서 추출한 지폐 이미지의 특징점을 훈련 및 판별 데이 터로 이용하여 위·변조 여부를 판별하였다.

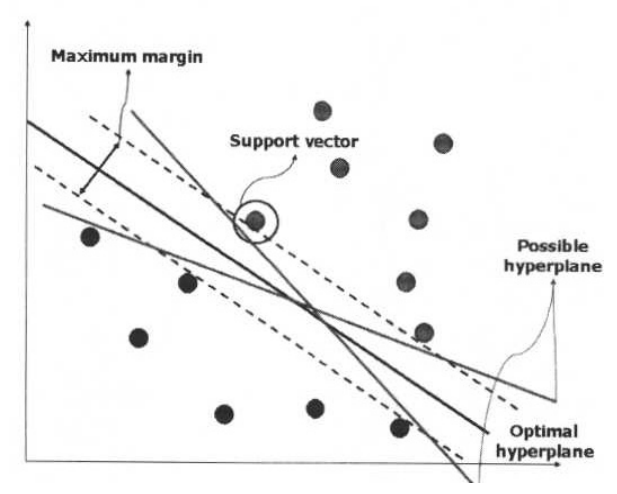

(a)

Principle of Support Vector Machines (SVM)

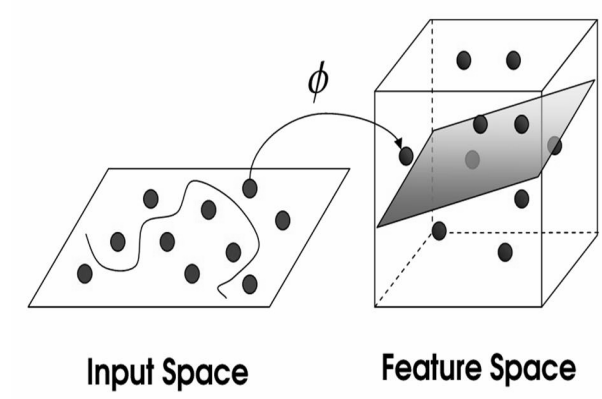

(b)

Fig. 13. (a) Binary classification and (b) mapping example using SVM classifier 


\section{4. 실험결과}

제안한 알고리즘의 성능 평가를 위하여 Table 2에 나타 난 것과 같이 4개 제조사(Xerox, $\mathrm{HP}$, Canon, Konica)에서 생산된 총 8개의 프린터(Xerox DCC 450, Xerox DCC 4300, Xerox DCC 5540, Xerox DCC 6550, HP, Canon iRC2620, Canon iRC3200N, Konica C250)를 사용하여 위조본을 제작 하였다. 지폐 이미지 데이터를 취득하기 위하여 위의 프린 터마다 36 장씩 제작한 1 만원권 위조지폐와 36 장의 1 만원권 원본 지폐를 스캐너를 통해 스캔하여 총 324 장 $(36 * 8+36)$ 의 훈련데이터를 수집하였다.

Fig. 14에는 실험에 사용된 원본 지폐 및 위변조 지폐의 예를 보여주고 있다. 수집한 데이터를 기반으로 하여 기존 연구에서 사용했던 위너필터와 이산웨이블릿변환에서 추출 한 특징과 제안하는 비지역적 평균 알고리즘을 통해 추출한 노이즈 특징을 이용하여, 명암도 동시발생 행렬을 생성하고, 통계적인 특징값을 계산한 후에 학습기반 데이터 분류기에 입력하여 위·변조 여부를 판별하였다.

Table 2. Manufacturer and model of each printing device

\begin{tabular}{|c|c|c|}
\hline Model ID & Manufacturer & Model \\
\hline X.1 & Xerox & DCC 450 \\
\hline X.2 & Xerox & DCC 4300 \\
\hline X.3 & Xerox & DCC 5540 \\
\hline X.4 & Xerox & DCC 6550 \\
\hline H.5 & HP & HP \\
\hline C.6 & Canon & iRC 2620 \\
\hline C.7 & Canon & iRC 3200N \\
\hline K.8 & Konica & C250 \\
\hline
\end{tabular}

\section{1 위·변조 판별 성능분석}

지폐 이미지의 위·변조 판별 성능분석을 위해, 앞서 수집 한 총 324장의 지폐 이미지 중에서 36장의 원본 지폐와 288 장의 위·변조 지폐의 그룹으로 나눠서 분류를 수행하였다.

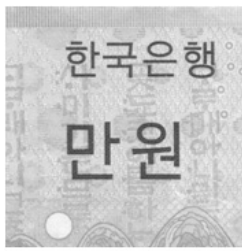

(a) 원몬

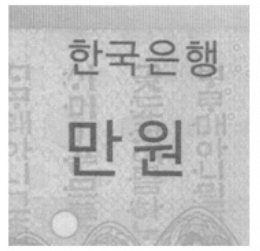

(c) $\mathrm{HP}$ 위조본

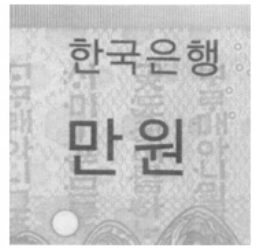

(b) Xerox 위조본

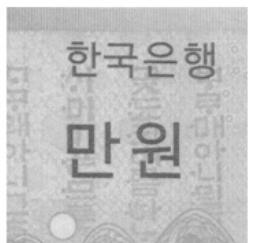

(d) Canon 위조본
Fig. 14. Original money and counterfeit money examples
Table 3에는 6회의 실험을 수행한 결과를 정리하였다. 프 린터 판별을 위해 사용되었던 기존의 위너필터 및 이산웨이 블릿변환과 본 논문에서 제시하는 방법인 비지역적 평균값 을 이용하여 각각 노이즈 특성을 추출하였다. 그 후에 추출 한 노이즈 특성들에 대하여 동일한 조건하에서 명암도 동시 발생 행렬을 이용하여 특징값을 계산하고, 서포트벡터머신 분류기를 이용하여 위변조를 판별하였다.

위너필터를 이용하였을 경우 평균 $89.50 \%$ 의 위변조 지폐 판별 정확도를 보이며, 이산웨이블릿변환은 평균 $87.40 \%$ 의 정확도를 보이는 것을 알 수 있다. 그러나 본 논문에서 제 안하는 비지역적 평균 알고리즘을 사용했을 경우 평균 $94.24 \%$ 의 정확도를 보여 기존 알고리즘보다 약 $5 \% 7 \%$ 정도의 높은 정확도를 나타냈다.

Table 3. Accuracy of each counterfeit money detection algorithm

\begin{tabular}{|c|c|c|c|}
\hline & $\begin{array}{c}\text { Wiener } \\
\text { filter }\end{array}$ & $\begin{array}{c}\text { Discrete Wavelet } \\
\text { Transform }\end{array}$ & Non-local mean \\
\hline 1 & 90.43 & 85.19 & 94.14 \\
\hline 2 & 87.35 & 86.42 & 94.75 \\
\hline 3 & 92.90 & 88.27 & 93.83 \\
\hline 4 & 90.74 & 87.35 & 94.75 \\
\hline 5 & 88.89 & 88.27 & 92.90 \\
\hline 6 & 86.73 & 88.89 & 95.06 \\
\hline Average & 89.50 & 87.40 & 94.24 \\
\hline
\end{tabular}

\section{2 위·변조 지폐 인쇄기기 판별 성능분석}

판별하고자 하는 지폐 이미지를 위·변조 지폐로 판별하였 을 때, 위·변조 지폐의 인쇄기기에 대한 판별 성능분석을 수 행하였다. 앞서 수집한 총 324장의 지폐 이미지를 지폐와 4 개의 제조사에서 생산된 총 8 개의 프린터로부터 생성한 위· 변조 지폐의 8개 그룹으로 나누어 분류를 수행하였다.

Table 4, Table 5, Table 6에는 위너필터, 이산웨이블릿변 환, 비지역적 평균 알고리즘을 각각 5 회의 실험을 수행한 결과에 대한 인쇄기기 판별 평균 정확도를 정리하였다. 각 번호에 해당하는 프린터의 제조사와 모델명은 Table 2에 제 시된 모델 $\mathrm{ID}$ 이다. Table 7 에는 각 노이즈 추출 방법을 사 용한 위변조를 수행하는데 사용된 인쇄기기의 판별률에 대 한 평균 정확도를 정리하였다.

위·변조 지폐의 인쇄기기 판별에서 위너필터는 평균 $91.11 \%$ 의 정확도를 보이며, 이산웨이블릿변환은 평균 $84.31 \%$ 의 정확도를 보임을 알 수 있다. 그러나 본 논문에서 제안하는 비지역적 평균 알고리즘을 사용했을 경우 평균 $93.76 \%$ 의 정확도를 보여 기존 알고리즘에 비해 약 2 9\%정 도 높은 정확도를 나타냈다.

또한 이산웨이블릿변환과 위너필터를 사용한 경우 동일한 제조사의 다른 모델에 대한 인쇄기기 판별 정확도가 떨어지 는데 비해, 비지역적 평균 알고리즘은 상대적으로 높은 정 확도를 보이는 것을 알 수 있다. 하지만 같은 제조사의 경 우 유사한 인쇄방식 때문에 모델간의 판별이 어려워 분류가 정확하게 수행되지 않아 다소 정확도가 떨어졌다. 
Table 4. Printing device identification accuracy using wiener filter $(\%)$

\begin{tabular}{|r|r|r|r|r|r|r|r|r|}
\hline & X.1 & X.2 & X.3 & X.4 & H.5 & C.6 & C.7 & K.8 \\
\hline X.1 & 84.44 & 15.56 & 0 & 0 & 0 & 0 & 0 & 0 \\
\hline X.2 & 21.11 & 78.89 & 0 & 0 & 0 & 0 & 0 & 0 \\
\hline X.3 & 0 & 0 & 86.67 & 13.33 & 0 & 0 & 0 & 0 \\
\hline X.4 & 0 & 0 & 14.44 & 85.56 & 0 & 0 & 0 & 0 \\
\hline H.5 & 0 & 0 & 0 & 0 & 100 & 0 & 0 & 0 \\
\hline C.6 & 0 & 0 & 0 & 0 & 0 & 98.33 & 1.667 & 0 \\
\hline C.7 & 0 & 0 & 0 & 0 & 0 & 5 & 95 & 0 \\
\hline K.8 & 0 & 0 & 0 & 0 & 0 & 0 & 0 & 100 \\
\hline
\end{tabular}

Table 5. Printing device identification accuracy using discrete wavelet transform (\%)

\begin{tabular}{|r|r|r|r|r|r|r|r|r|}
\hline & X.1 & X.2 & X.3 & X.4 & H.5 & C.6 & C.7 & K.8 \\
\hline X.1 & 58.89 & 40.56 & 0 & 0 & 0.56 & 0 & 0 & 0 \\
\hline X.2 & 31.11 & 68.33 & 0 & 0 & 0.56 & 0 & 0 & 0 \\
\hline X.3 & 0 & 0 & 80 & 20 & 0 & 0 & 0 & 0 \\
\hline X.4 & 0 & 0 & 22.22 & 77.78 & 0 & 0 & 0 & 0 \\
\hline H.5 & 0 & 0 & 0 & 0 & 99.44 & 0 & 0 & 0.56 \\
\hline C.6 & 0 & 0 & 0 & 0 & 0 & 92.78 & 7.22 & 0 \\
\hline C.7 & 0 & 0 & 0 & 0 & 0 & 2.22 & 97.78 & 0 \\
\hline K.8 & 0 & 0 & 0 & 0 & 0.56 & 0 & 0 & 99.44 \\
\hline
\end{tabular}

Table 6. Printing device identification accuracy using non-local mean algorithm (\%)

\begin{tabular}{|r|r|r|r|r|r|r|r|r|}
\hline & X.1 & X.2 & \multicolumn{1}{|c}{ X.3 } & \multicolumn{1}{|c|}{ X.4 } & H.5 & C.6 & C.7 & K.8 \\
\hline X.1 & 85.56 & 14.44 & 0 & 0 & 0 & 0 & 0 & 0 \\
\hline X.2 & 11.11 & 88.89 & 0 & 0 & 0 & 0 & 0 & 0 \\
\hline X.3 & 0 & 0 & 92.22 & 7.78 & 0 & 0 & 0 & 0 \\
\hline X.4 & 0 & 0 & 14.44 & 85.56 & 0 & 0 & 0 & 0 \\
\hline H.5 & 0 & 0 & 0 & 0 & 100 & 0 & 0 & 0 \\
\hline C.6 & 0 & 0 & 0 & 0 & 0 & 100 & 0 & 0 \\
\hline C.7 & 0 & 0 & 0 & 0 & 0 & 2.22 & 97.78 & 0 \\
\hline K.8 & 0 & 0 & 0 & 0 & 0 & 0 & 0 & 100 \\
\hline
\end{tabular}

Table 7. Average printing device identification accuracy of counterfeit money (\%)

\begin{tabular}{|c|c|c|c|}
\hline & Wiener filter & $\begin{array}{c}\text { Discrete Wavelet } \\
\text { Transform }\end{array}$ & Non-local mean \\
\hline $\begin{array}{l}\text { Average } \\
\text { accuracy }\end{array}$ & 91.11 & 84.31 & 93.76 \\
\hline
\end{tabular}

\section{5. 결 론}

고성능 디지털 인쇄기기 보급의 확대와 강력한 이미지 편 집 소프트웨어의 출현은 지폐의 위조나 변조가 용이해 그에 따른 범죄가 늘고 있다. 본 논문에서는 이러한 문제를 해결 하는 방안을 제시하고자 지폐의 고유한 특징을 추출하여 위
변조를 판별하는 기술을 제안하였다. 위·변조 지폐 판별을 위하여 비지역적 평균 알고리즘을 이용하여 위변조된 지폐 의 인쇄로 인한 노이즈 특성을 추출하고, 명암도 동시발생 행렬을 생성한 후, 다양한 질감 분석을 통해 지폐의 특성을 나타내는 특징값을 추출한 후에, 학습기반 데이터 분류기를 훈련하고, 이를 기반으로 위·변조 여부를 판별하였다.

실험에 따르면 위·변조 지폐 판별에 있어서 비지역적 평 균 알고리즘을 적용하면 평균 $94.24 \%$ 의 정확도를 보였고, 기존의 알고리즘에 비하여 정확도를 향상하였다. 또한, 위· 변조 지폐로 판별 시 제조사에 대한 판별에 있어서도 비지 역적 평균 알고리즘을 적용하면 평균 $93.76 \%$ 의 정확도를 보 여 위·변조 지폐 생성 시에 사용한 인쇄기기의 판별을 할 수 있었다. 이를 통해 위·변조 지폐 발견 시, 위·변조 지폐 의 제조과정에 사용된 인쇄기기를 정확하게 판별함으로써 위·변조 범죄에 대한 단서를 제공할 수 있다. 하지만 노이즈 특성을 추출하는 비지역적 평균 알고리즘을 수행함에 있어 많은 시간이 소모되므로, 이에 최적화된 알고리즘에 대한 추가 연구가 필요하다. 또한 판별의 정확도 향상을 위하여 지폐의 고유한 특징인 특징점을 추출하는 알고리즘에 대한 연구가 필요하다.

본 논문에서는 각각의 세부 기술들에 대해서 새롭게 제안 하는 것은 아니지만, 범용 스캐닝 장비들을 통하여 위변조 지폐를 탐지하기 위한 시도와 이에 대한 최적의 절차(알고 리즘)을 제안함으로서 기여를 했다

\section{참 고 문 헌}

[1] H.-Y. Lee, J.-Y. Baek, S.-G. Kong, H.-S. Lee, J.-H. Choi, "Color Laser Printer Forensics through Wiener Filter and Gray Level Co-occurrence Matrix”, 정보과학회논문지: 소프트 웨어 및 응용, Vol.37, No.8, pp.599-610, 2010.

[2] J.-H. Choi, "Color laser printer identification using color noise features”, MCS 09030, MS thesis, Korea Advanced Institute of Science and Technology, Proc. of ACM Multimedia and Security (MMSEC 2010), pp.19-24. 2009.

[3] J.-Y. Baek, H.-S. Lee, S.-G. Kong, J.-H. Choi, Y.-M. Yang, H.-Y. Lee, "Color Laser Printer Identification through Discrete Wavelet Transform and Gray Level Co-occurrence Matrix", 정보처리학회논문지, Vol.17-B, No.3, pp.197-206, 2010.6

[4] S.-J. Ryu, H.-Y. Lee, Dong-Hyuck Im, Jungho Choi, and Heung-Kyu Lee, "Electrophotographic Printer Identification by Halftone Texture Analysis," Proc. of IEEE International Conference on Acoustics, Speech and Signal Processing (ICASSP2010), pp.1846-1849, 2010.

[5] A. Buades, B. Coll, J.-M. Morel. "A non-local algorithm for image denoising”, Computer Vision and Pattern Recognition, 2005.

[6] R. M. Haralick, K. Shanmugam, and I. Dinstein, "Textural features for image classification," IEEE Trans. on Systems, Man, Cybernetics, Vol.3, No.6, pp.610-621, 1973. 
[7] Wikipedia, "Support Vector Machine", http:// en.wikipedia. org/wiki/Support_vector_machine

[8] C. -C. Chang and C.- J. Lin, "LIBSVM: a library for support vector machines," Software available at [Internet] http:// www. csie.ntu.edu.tw/ ${ }^{\sim}$ cjlin/libsvm/, 2001.

[9] C. - W. Hsu, C. - C. Chang, and C. - J Lin, "A practical guide to support vector classification," [Internet] http://www.csie. ntu.edu.tw/ cjlin/papers/guide/guide.pdf

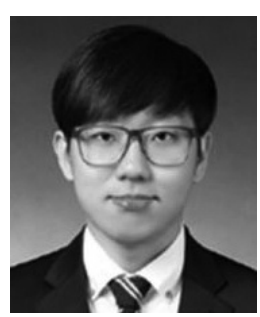

\section{지 상 근}

e-mail : jisk0117@naver.com

2007년 현 재 국립금오공과대학교 컴퓨터소프트웨어공학과 학사과정

관심분야: 영상처리, 디지털포렌식 등

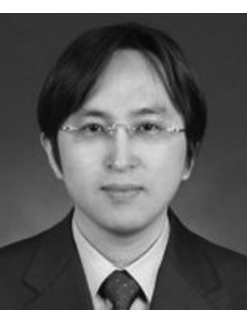

\section{이 해 연}

e-mail : haeyeoun.lee@kumoh.ac.kr 1997년 성균관대학교 정보공학과(학사) 1999년 한국과학기술원 전산학과 (공학석사)

2006년 한국과학기술원 전자전산학과 전산학전공(공학박사)

2001년 2006년 (주)쎄트렉아이 선임연구원

2006년 2007년 코넬대학교 박사후연구원

2008년 현 재 국립금오공과대학교 컴퓨터소프트웨어공학과 교수

관심분야: 멀티미디어, 영상처리, 콘텐츠보안, 디지털워터마킹 